\title{
PRODUTIVIDADE E RENDIMENTO COMERCIAL DE BULBOS DE CEBOLA EM FUNÇÃO DA DENSIDADE DE CULTIVO
}

\author{
Productivity and commercial yield of onion bulbs in function of growth density \\ João Eduardo Baier ${ }^{1}$, Juliano Tadeu Vilela de Resende², Alexandre Gonçalves Galvão ${ }^{3}$, \\ Guilherme Mendes Battistelli ${ }^{4}$, Maicon Modesto Machado ${ }^{5}$, Marcos Ventura Faria ${ }^{6}$
}

\begin{abstract}
RESUMO
A distribuição adequada das plantas de cebola (Allium cepa L.) na lavoura torna-se necessária devido a influência sobre a competição por água, luz e nutrientes, determinando o tamanho dos bulbos e a produtividade total. Objetivou-se, no trabalho, avaliar a produtividade e os padrões comerciais de bulbos de cebola, em função da densidade de plantio adotada. As mudas de cebola foram produzidas em bandejas de poliestireno de 200 células, com substrato comercial Plantimax®. O experimento foi instalado em delineamento experimental de blocos casualizados (DBC) com 4 repetições, com parcelas de $2 \mathrm{~m}^{2}$. Utilizou-se a cultivar Buccaneer, nas densidades de 50, 75 e 100 plantas $\mathrm{m}^{-2}$. Foram avaliadas a produção comercial, a produção total e a massa média de bulbos. Observou-se que a densidade de 100 plantas $\mathrm{m}^{-2}$ proporcionou a maior produtividade $\left(92,20 \mathrm{t} \mathrm{ha}^{-1}\right)$. No entanto, a menor densidade de plantas avaliada proporcionou bulbos com a maior massa média $(171 \mathrm{~g})$. As densidades de 50 e 75 plantas $\mathrm{m}^{-2}$ apresentaram os maiores valores distribuídos na classe 4 (> que 70 até $90 \mathrm{~mm}$ de diâmetro) e 3 cheio (> que 60 até $70 \mathrm{~mm}$ de diâmetro), respectivamente. A densidade de 100 plantas $\mathrm{m}^{-2}$ proporcionou uma maior quantidade de bulbos na classificação 3 cheio. Os resultados obtidos demonstraram que o aumento na densidade de plantas proporcionou uma maior produtividade, uma menor massa média de bulbos e uma maior produção na classificação comercial 3 cheio, considerada ideal para comercialização em função da preferência pelos consumidores.
\end{abstract}

Termos para indexação: Allium cepa, densidade populacional, classificação comercial.

\section{ABSTRACT}

The adequate distribution of onions (Allium cepa L.) within a crop becomes necessary due to their influence on the competition for water, light, and nutrients, which determines the size of the bulbs and the total yield. The goal of this work was to evaluate the yield and commercial pattern of onion bulbs as a function of the crop density employed. The onion seedlings were produced on polystyrene trays with 200 cells filled with commercial substrate Plantimax ${ }^{\circledR}$. The experiment was carried out according to a randomized block design (RBD), with four replications and 2- $\mathrm{m}^{2}$ plots. The cultivar Buccaneer was evaluated in densities of 50, 75, and $100 \mathrm{plants}^{-2}$. The commercial bulb yield, the total yield, and the average mass of bulbs were evaluated. The density of $100 \mathrm{plants}^{-2}$ provided the greatest yield $\left(92.20 \mathrm{t} \mathrm{ha}^{-1}\right)$. However, the lower density of plants provided bulbs with the greatest average mass (171g). Densities of 50 and 75 plants $\mathrm{m}^{-2}$ presented the greatest values distributed in class 4 (> 70 up to $90 \mathrm{~mm}$ of diameter) and 3 full (> 60 up to $70 \mathrm{~mm}$ of diameter), respectively. Density of 100 plants $\mathrm{m}^{-2}$ provides a larger amount of bulbs in the 3 -full classification. The results obtained in this experiment showed that an increase in the density of plants provided greater yield, smaller average mass of bulbs and greater production in the commercial 3-full classification, which is considered ideal for the market due to the consumers' preference.

Index terms: Allium cepa, population density, commercial classification.

(Recebido em 1 de outubro de 2007 e aprovado em 23 de abril de 2008)

\section{INTRODUÇÃo}

A produção brasileira de cebola (Allium cepa $\mathrm{L}$.) em 2006 foi de 53,6 milhões de toneladas, colhidas em uma área de 3,1 milhões de hectares, o que proporcionou uma produtividade média de 17,5 tha-1 (FAO, 2007). No Brasil, no mesmo período, a produtividade média se situou em $17,9 \mathrm{t} \mathrm{ha}^{-1}$ (IBGE, 2007).

\footnotetext{
${ }^{1}$ Graduando em Agronomia - Universidade Estadual do Centro-Oeste do Paraná/ UNICENTRO - Rua Simeão Camargo Varela de Sá - Campus Universitário do CEDETEG - Cx. P. 3010 - 85040-080 - Guarapuava, PR - joão_bayer@hotmail.com - Bolsista PIBIC/ CNPq

${ }^{2}$ Engenheiro Agrônomo, Doutor em Fitotecnia - Departamento de Agronomia/ DEAGRO - Universidade Estadual do Centro-Oeste do Paraná/ UNICENTRO - Rua Simeão Camargo Varela de Sá - Campus Universitário do CEDETEG - Cx. P. 3010 - 85040-080 - Guarapuava, PR jresende@unicentro.br

${ }^{3}$ Graduando em Agronomia - Universidade Estadual do Centro-Oeste do Paraná/ UNICENTRO - Rua Simeão Camargo Varela de Sá - Campus Universitário do CEDETEG - Cx. P. 3010 - 85040-080 - Guarapuava, PR - galvaox@gmail.com

${ }^{4}$ Graduando em Agronomia - Universidade Estadual do Centro-Oeste do Paraná/ UNICENTRO - Rua Simeão Camargo Varela de Sá - Campus Universitário do CEDETEG - Cx. P. 3010 - 85040-080 - Guarapuava, PR - gmendes@unicentro.br - Bolsista de Iniciação Científica

${ }^{5}$ Graduando em Agronomia - Universidade Estadual do Centro-Oeste do Paraná/ UNICENTRO - Rua Simeão Camargo Varela de Sá - Campus Universitário do CEDETEG - Cx. P. 3010 - 85040-080 - Guarapuava, PR - mmachado@unicentro.br - Bolsista de Iniciação Científica

${ }^{6}$ Engenheiro Agrônomo, Doutor em Genética e Melhoramento de Plantas - Departamento de Agronomia/ DEAGRO - Universidade Estadual do CentroOeste do Paraná/ UNICENTRO - Rua Simeão Camargo Varela de Sá - Campus Universitário do CEDETEG - Cx. P. 3010 - 85040-080 - Guarapuava PR - mfaria@unicentro.br
} 
A cebola é uma das hortaliças de grande importância no Brasil, suplantada apenas pelo tomate e pela batata (CARDOSO \& COSTA, 1999), sendo preferencialmente consumida na forma in natura, em saladas, temperos e condimentos.

No Brasil, o cultivo da cebola se estende desde a região Sul até a região Nordeste, destacando-se os estados de Santa Catarina, Rio Grande do Sul, São Paulo, Paraná, Bahia, Pernambuco e Minas Gerais, responsáveis pela quase totalidade da produção nacional (BOEING, 2002).

No Paraná, a cebola é uma das principais culturas de subsistência para um grande número de pequenos produtores, com destaque para as regiões que envolvem os municípios de Imbituva e Irati. Na safra 2005/2006, a área cultivada no Paraná foi de 6.431 ha com produtividade média de 13,9 $\mathrm{t} \mathrm{ha}^{-1}$ (SEAB/DERAL, 2006). No entanto, a falta de planejamento da safra e a carência de informações técnicas sobre o sistema de cultivo, principalmente com relação à densidade de plantas utilizada, são alguns dos fatores responsáveis pela baixa produtividade e qualidade comercial da cebola na região. A densidade de plantio mais freqüentemente adotada pelos produtores de cebola do estado do Paraná situa-se em torno de 44 a 50 plantas $\mathrm{m}^{-2}$, ou seja, em espaçamentos de 12,5 x 20,0cm e 10,0 x 20,0cm, respectivamente, contribuindo dessa forma para as baixas produtividades observadas.

Resende et al. (2005) verificaram aumento na produtividade de cebola da cultivar Texas Grano 502 PRR, nas condições do Vale do São Francisco, à medida que o espaçamento entre linhas e entre plantas foi reduzido, sendo a maior produtividade obtida com o espaçamento de 0,15 $\mathrm{m}$ entre linhas e $0,10 \mathrm{~m}$ entre plantas.

Avaliando a influência da densidade de plantas sobre a produtividade de cebola em três espaçamentos entre linhas $(0,20 \mathrm{~m}, 0,30 \mathrm{~m}$ e $0,40 \mathrm{~m})$ com espaçamento entre plantas de $0,08 \mathrm{~m}$, Lopes et al. (2004) constataram que, no menor espaçamento $(0,20 \times 0,08 \mathrm{~m})$, foi obtida a maior produtividade comercial e a menor massa fresca dos bulbos. Kanton et al. (2002) observaram aumento na produtividade com o incremento da densidade de plantio de 37,04 para 156,25 plantas por metro quadrado, porém com redução na altura de planta e na massa fresca do bulbo, sendo que densidades acima de 76,92 plantas $\mathrm{m}^{-2}$ proporcionam maiores produtividades de bulbos comerciais.

A densidade ideal de plantas por hectare consiste numa condição de extrema importância na determinação da produtividade e produção comercial de bulbos de cebola. No entanto, em função da utilização da técnica de semeadura direta, o número de plantas por hectare pode se tornar incipiente, comprometendo drasticamente a produtividade. A competição entre plantas aumenta a concorrência por luz, água, $\mathrm{CO}_{2}$ oxigênio e nutrientes minerais, modificando dessa forma o processo de bulbificação (MASCARENHAS, 1993). Segundo Cardoso \& Costa (1999) o aumento da densidade de plantio promove a aceleração da maturação dos bulbos, sendo o cultivo em alta densidade um fator que leva ao menor crescimento da planta (MASCARENHAS, 1993), diminuição da massa média de bulbos, podendo ter grande influência na produtividade da cultura (FILGUEIRA, 2005; SANTOS et al., 2000).

O aumento da população de plantas pode contribuir para melhorar a exploração tanto do ambiente quanto da cultivar, tendo como conseqüência o aumento da produtividade. $\mathrm{O}$ adequado seria o estabelecimento de uma população ótima, que maximizaria a exploração desses fatores, garantindo a maior produtividade. Estudos realizados por vários pesquisadores, nas condições de cultivo brasileiras, mostram que o número de plantas por área é o fator de suma importância na obtenção de elevada produção (ANEZ \& TAVIRA, 1986; COSTA et al., 2000). Mascarenhas et al. (1993) afirmam que a baixa qualidade e produtividade da cebola são atribuídas à densidade de plantio inadequada. A produtividade, a produção comercial e a proporção de bulbos com menor massa média aumentaram em função do incremento na densidade mediante redução no espaçamento entre linhas e entre plantas (BOFF et al., 1998; GALMARINI \& GASPERA, 1995; LOPES, 1987; STOFFELLA, 1996). Assim, o estudo da densidade populacional torna-se de grande importância para que se possa ter êxito com a cultura da cebola.

Objetivou-se, no presente trabalho, avaliar a produtividade, o peso médio e os padrões comerciais de bulbos de cebola em função da densidade de plantio, na região centro-sul do Paraná.

\section{MATERIAL E MÉTODOS}

O trabalho foi conduzido no Setor de Olericultura da Universidade Estadual do Centro-Oeste do Paraná (UNICENTRO-PR) em latitude de 2523'36", longitude de $51^{\circ} 27^{\prime} 19^{\prime \prime}$ e altitude de $1.120 \mathrm{~m}$, em clima subtropical úmido mesotérmico, com o solo classificado em Cambissolo Háplico (EMBRAPA, 1999).

$\mathrm{O}$ experimento foi instalado em parcelas de $2 \mathrm{~m}^{2}$, com área útil de $1,50 \mathrm{~m}^{2} \mathrm{em}$ delineamento experimental de blocos casualizados completos com quatro repetições. Utilizou-se o híbrido de cebola Buccaneer $\mathrm{F}_{1}$ nas densidades de 50, 75 e 100 plantas $\mathrm{m}^{-2}$, correspondendo aos espaçamentos de $10,0 \mathrm{~cm}$ x 20,0 cm, 10,0 cm x 15,0 cm e 
$10,0 \mathrm{~cm} \times 10,0 \mathrm{~cm}$ entre linhas e entre plantas, respectivamente. $\mathrm{O}$ híbrido Buccaneer $\mathrm{F}_{1}$ apresenta bulbos de formato globular e coloração amarelo-escura, com boa tolerância a doenças foliares e excelente pós-colheita, sendo indicado para plantio entre maio e junho, com ciclo variando de 130 a 135 dias.

Os canteiros foram levantados com uso de rotoencanteirador em dimensões equivalentes a $1,00 \mathrm{~m}$ de largura e $0,25 \mathrm{~m}$ de altura. As mudas foram produzidas em bandejas de poliestireno de 200 células, com substrato comercial Plantmax ${ }^{\circledR}$ e mantidas sob estufa e irrigadas por microaspersão. As mudas foram transplantadas para o campo com, aproximadamente, $15 \mathrm{~cm}$ de altura.

No plantio, foram aplicados $600 \mathrm{~kg} \mathrm{ha}^{-1}$ do formulado NPK 04-14-08, de acordo com o recomendado para a cultura e com base na análise de solo. Para adubação em cobertura foram aplicados $80 \mathrm{Kg} \mathrm{ha}^{-1}$ de $\mathrm{N}$ na forma de uréia e $60 \mathrm{Kg} \mathrm{ha}^{-1}$ de $\mathrm{K}_{2} \mathrm{O}$ na forma de cloreto de potássio, parcelado em duas vezes, aos 30 e 60 dias após o transplantio. A irrigação foi realizada por aspersão duas vezes por semana, quando necessária, sendo interrompida por ocasião da colheita. $\mathrm{O}$ controle de plantas daninhas foi realizado manualmente no início do desenvolvimento vegetativo. $\mathrm{O}$ controle de pragas e doenças foi realizado quando necessário, obedecendo ao recomendado para a cultura da cebola, nas regiões produtoras do Paraná.

O ponto de colheita foi determinado pelo secamento das folhas baixeiras e pelo "estalo" de cerca de $80 \%$ das plantas. Após a colheita, os bulbos foram mantidos por 4 dias no campo em período sem precipitação, para início do processo de "cura" e posteriormente acondicionados em galpão, onde foram submetidos ao processo de limpeza (toalete) e finalização da "cura". Em seqüência, os bulbos foram contados, pesados e classificados de acordo com o diâmetro transversal (portaria 529 de 18 de março de 1995, MAPA), da seguinte forma: classe 1 (entre 15 e $35 \mathrm{~mm}$ ); 2 (entre 36 e $50 \mathrm{~mm}$ ); 3 (entre 51 e $60 \mathrm{~mm}$ ); 3 cheio (entre 61 e $70 \mathrm{~mm}$ ); 4 (entre 71 e $90 \mathrm{~mm}$ ) e 5 (maior que $90 \mathrm{~mm}$ ). Foi determinada a produtividade em $\mathrm{t} \mathrm{ha}^{-1}$ considerando 7.500 $\mathrm{m}^{-2}$ de área útil e a massa média de bulbos. Os dados foram submetidos à análise de regressão e de variância e as médias comparadas pelo teste de Tukey, a 5\% de probabilidade.

\section{RESULTADOS E DISCUSSÃO}

Observou-se que a produtividade de bulbos aumentou linearmente em função do aumento na densidade de plantas, sendo observadas diferenças estatísticas para as características avaliadas (Figura 1). A maior densidade utilizada (100 plantas $\mathrm{m}^{-2}$ ) foi a mais efetiva em aumentar a produtividade $\left(92,20 \mathrm{t} \mathrm{ha}^{-1}\right)$, contribuindo com um incremento de 28,05 e 14,95 toneladas, quando comparada às densidades de 50 e 75 plantas $\mathrm{m}^{-2}$, respectivamente (Figura 1). No entanto, a menor densidade de plantas avaliada proporcionou maior massa média de bulbos (171g) quando comparada à densidade de 100 plantas $\mathrm{m}^{-2}(103 \mathrm{~g})$, sendo estatisticamente superior. $\mathrm{O}$ estande de 75 plantas $\mathrm{m}^{-2}$ apresentou massa média de bulbo equivalente a $164 \mathrm{~g}$, porém não diferindo estatisticamente da menor densidade de plantas utilizada (Figura 2). A redução da massa média de bulbos, em consequiência do aumento da densidade, também foi observada por Santos et al. (2000) que encontraram reflexos negativos na produtividade quando o espaçamento entre plantas foi aumentado, o que condiz com os resultados do presente trabalho. Reghin et al. (2004) verificaram, em trabalhos realizados em Ponta Grossa-PR, que o rendimento total de bulbos de cebola foi aumentado de acordo com o incremento na densidade de plantas, porém com redução do tamanho dos bulbos. Rumpel \& Felczynski (2000) também verificaram que a produção de bulbos graúdos é gradativamente decrescente com o aumento da população de plantas. Em seus estudos puderam verificar que os maiores bulbos foram produzidos nas populações de 20 a 40 plantas $\mathrm{m}^{-2}$, enquanto que os menores foram alcançados na população de 140 plantas $\mathrm{m}^{-2}$.

Os resultados obtidos no presente trabalho evidenciam uma relação inversa entre a densidade de plantio e o tamanho do bulbo, corroborando com os resultados de Hatridge-esh \& Bennett (1980), Resende \& Costa (2006), Rumpel \& Felczynski (2000) e Stoffella (1996).

Reghin et al. (2004) ao avaliarem o rendimento de bulbos das cultivares Crioula e Bola Precoce, utilizando espaçamento de $0,40 \mathrm{~m}$ entre linhas e quatro diferentes espaçamentos entre plantas $(5,8,11 \mathrm{e} 14 \mathrm{~cm})$ observaram que, na menor densidade não houve diferenças entre as duas cultivares quanto à produtividade e proporção de bulbos comercializáveis, contudo verificaram comportamento diferenciado entre genótipos nas demais densidades de plantio. Todavia, os resultados obtidos por Siqueira (2004) não corroboraram com os observados no trabalho, pois a produtividade aumentou linearmente com a diminuição do estande.

A classificação dos bulbos segundo a classe de tamanho é outro indicador da qualidade de produção alcançada. Segundo Souza \& Resende (2002), o mercado consumidor nacional prefere bulbos de tamanho médio, com massas de 80 a 100 gramas e diâmetro transversal, variando entre 40 a $80 \mathrm{~mm}$.

Para todas as densidades utilizadas não foram observados bulbos considerados refugo, ou seja, pertencentes à classe zero. As densidades de 50 e 75 plantas $\mathrm{m}^{-2}$ 


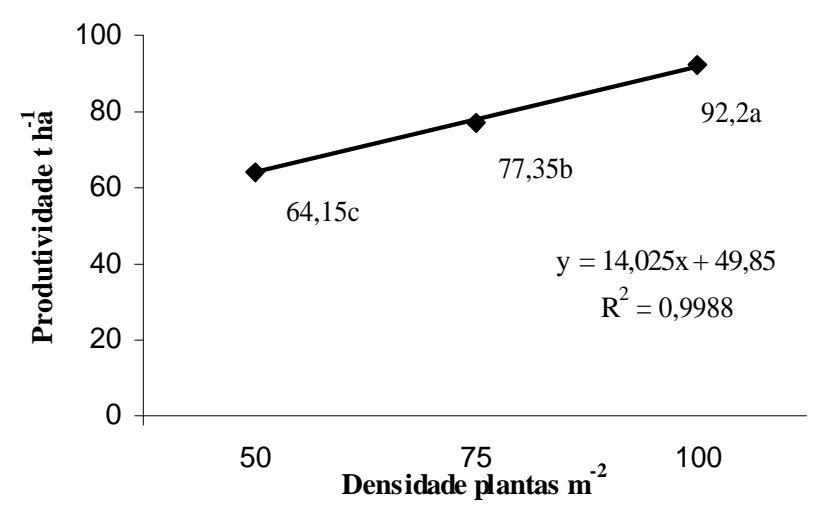

Figura 1 - Produtividade de bulbos de cebola, em função de diferentes densidades de plantio.

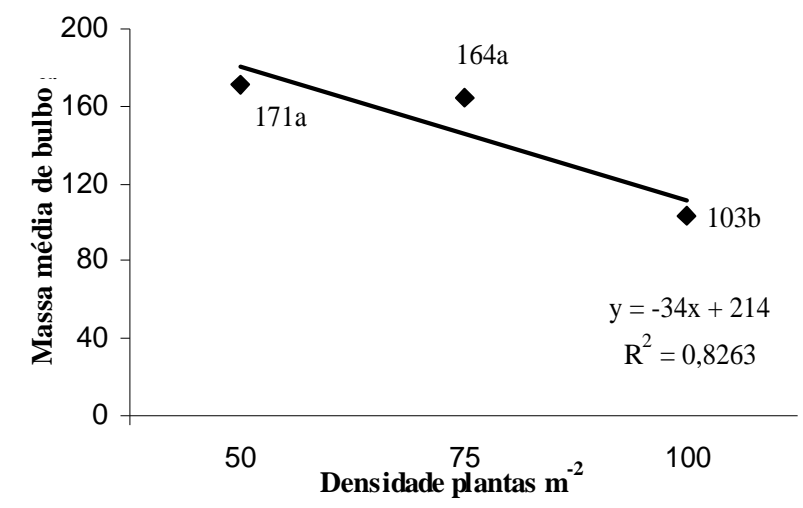

Figura 2 - Massa média de bulbos de cebola, em função de diferentes densidades de plantio.

apresentaram comportamentos semelhantes em relação à distribuição da produção nas classes comerciais, sendo que os maiores valores foram observados nas classes 4 (> 70 até $90 \mathrm{~mm}$ de diâmetro) e 3 cheio (> 60 até $70 \mathrm{~mm}$ de diâmetro), respectivamente. À medida que se aumentou a densidade (100 plantas $\mathrm{m}^{-2}$ ), observou-se uma redução proporcional no diâmetro de bulbos, possibilitando a obtenção de bulbos com classificação na classe 3 (entre 51 e $60 \mathrm{~mm}$ ) e 3 cheio (entre 61 e $70 \mathrm{~mm}$ ), ideais por serem preferidos pelas donas de casa (SILVA et al., 1991) (Tabela 1). Dessa forma, para que se obtenham maiores porcentagens nessa classe, a elevada densidade atuou positivamente, indicando que a população de plantas passa a ser definida pela classificação dos bulbos, que é importante fator qualitativo a ser estabelecido. Todavia, os resultados obtidos por Vargas et al. (2007) não corroboram com os observados no trabalho, pois houve um incremento na porcentagem de bulbos na classe 3 cheio, com o aumento no espaçamento entre plantas.
Tabela 1 - Distribuição em classes comerciais da produção de bulbos de cebola $\left(\mathrm{kg} \mathrm{ha}^{-1}\right.$, considerando $7.500 \mathrm{~m}^{-2}$ de área útil), em função de diferentes densidades de plantio.

\begin{tabular}{cccc} 
Classes & \multicolumn{3}{c}{ Densidades de plantas $\mathrm{m}^{-2}$} \\
\cline { 2 - 4 } Comerciais & 50 & 75 & 100 \\
\hline 1 & $145,5 \mathrm{c}$ & $126,7 \mathrm{c}$ & $7.235,0 \mathrm{~d}$ \\
2 & $511,0 \mathrm{c}$ & $1.261,2 \mathrm{c}$ & $7.578,2 \mathrm{c}$ \\
3 & $1.687,7 \mathrm{bc}$ & $2.789,2 \mathrm{bc}$ & $15.478,2 \mathrm{~b}$ \\
3 cheio & $3.361,2 \mathrm{bc}$ & $7.936,0 \mathrm{~b}$ & $24.806,2 \mathrm{a}$ \\
4 & $14.984,5 \mathrm{a}$ & $26.559,5 \mathrm{a}$ & $20.343,7 \mathrm{ab}$ \\
5 & $631,9 \mathrm{c}$ & $4.434,5 \mathrm{bc}$ & - \\
\hline
\end{tabular}

Médias seguidas da mesma letra não difere estatisticamente pelo teste de Tukey $(\alpha=0,05)$

A determinação correta da população a ser utilizada no cultivo da cebola é de fundamental importância na obtenção de boa produtividade e, principalmente, na qualidade comercial de bulbos.

Os resultados obtidos com o aumento da densidade de plantas por $\mathrm{m}^{2}$ podem contribuir significativamente para aumentar a produtividade média no Estado do Paraná (RESENDE et al., 2002) e, principalmente, na produção de bulbos classificados na classe 3 cheio, ideal para a comercialização.

\section{CONCLUSÕES}

A densidade de 50 plantas $\mathrm{m}^{-2}$ proporcionou a menor produtividade e bulbos com maior massa média, não preferidos para consumo doméstico, no entanto, ideal para a utilização em fast food.

A densidade de 75 plantas $\mathrm{m}^{-2}$ proporcionou produtividade intermediária e maior concentração de bulbos distribuídos nas classes 3 cheio, 4 e 5, ideal para atender a ambos os mercados.

A densidade de 100 plantas $\mathrm{m}^{-2}$ proporcionou maior produtividade e aumento na porcentagem de bulbos de interesse comercial (classes 3 cheio e 4).

\section{REFERÊNCIAS BIBLIOGRÁFICAS}

ANEZ, R. B.; TAVIRA, D. E. Aplicacion de N, P y K a diferentes poblaciones de plantas de cebolla. Turrialba, San José, v. 36, n. 2, p. 163-170, 1986.

BOEING, G. Fatores que afetam a qualidade da cebola na agricultura familiar catarinense. Florianópolis: Instituto CEPA/SC, 2002. 80 p. 
BOFF, P.; HENRI, S.; GONÇALVES, P. A. S. Influência da densidade de plantas na ocorrência de doenças foliares e produção de bulbos de cebola. Fitopatologia Brasileira, Brasília, v. 23, n. 4. p. 448-452, 1998.

CARDOSO, A. I. I.; COSTA, C. P. da. Produção de bulbilhos de cebola em bandejas de isopor. Scientia Agrícola, Piracicaba, v. 56, n. 4, p. 969-974, 1999.

COSTA, N. D.; RESENDE, G. M. de; DIAS, R. de C. S. Avaliação de cultivares de cebola em Petrolina-PE. Horticultura Brasileira, Brasília, v. 18, n. 1, p. 57, 2000.

EMPRESA BRASILEIRA DE PESQUISA AGROPECUÁRIA. Sistema brasileiro de classificação de solos. Brasília, DF, 1999. 412 p.

FAO. Agricultural production, primary crops.

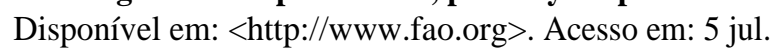
2007.

FILGUEIRA, F. A. R. Novo manual de olericultura: agrotecnologia moderna na produção e comercialização de hortaliças. Viçosa: UFV, 2005. 402 p.

GALMARINI, C. R.; GASPERA, P. G. Efecto de la epoca de transplante y la densidad de plantacion en el cultivo de cebolla tipo Valenciana. Horticultura Argentina, Mendoza, v. 14, n. 37, p. 23-29, 1995.

HATRIDGE-ESH, K. A.; BENNETT, J. P. Effects of seed weight, plant density and spacing on yield responses of onion. Journal of Horticultural Science, v. 55, n. 3, p. 247-252, 1980.

INSTITUTO BRASILEIRO DE GEOGRAFIA E ESTATÍSTICA. Produção agrícola. Disponível em: '́ttp://www.sidra.ibge.gov.br

KANTON, R. A. L.; ABBEY, L.; HILLA, R. G.; TABIL, M. A.; JAN, N. D. Density affects plant development and yield of bulb onion (Allium cepa L.) in Northern Ghana. Journal Vegetable Crop Production, v. 8, p. 525,2002 .

LOPES, J. F. Effects of planting dates and spacing on several characteristics of short day onion varieties grown in South Texas. 1987. 111 f. Thesis (Ph.D.) - Texas University, Texas, 1987.
LOPES, M. C.; CZEPAK, M. P.; SIRTOLI, L. F. Avaliação de diferentes espaçamentos na produtividade de três cultivares de cebola. In: CONGRESSO BRASILEIRO DE OLERICULTURA, 44., 2004, Campo Grande, MS. Anais.. Campo Grande, 2004. CD-ROM.

\section{MASCARENHAS, M. H. T. Cebola. Informe}

Agropecuário, Belo Horizonte, v. 14, n. 163, p. 69-73, 1993.

REGHIN, M. Y.; OTTO, R. F.; JACOBY, C. F. S.; OLINIK, J. R.; OLIVEIRA, R. P. Efeito da densidade de plantas no rendimento de bulbos com diferentes cultivares de cebola. In: CONGRESSO BRASILEIRO DE OLERICULTURA, 44., 2004, Campo Grande, MS. Anais... Campo Grande, 2004. CD-ROM.

RESENDE, G. M.; COSTA, N. D. Produtividade e massa fresca de bulbos de cebola sob densidades de plantio no Vale do São Francisco. Horticultura Brasileira, Brasília, v. 24, p. 228-232, 2006.

RESENDE, G. M.; COSTA, N. D.; ALVARENGA, M. A. R. Rendimento e perda de peso de bulbos de cebola cv. Texas Grano 502 PPR em diferentes espaçamentos de plantio. Caatinga, Mossoró, v. 18, n. 1, p. 28-34, 2005.

RESENDE, L. M. A.; MASCARENHAS, M. H. T.; SIMÃO, M. L. R. Panorama da produção e da comercialização da cebola em Minas Gerais. Informe Agropecuário, Belo Horizonte, v. 23, n. 218, p. 7-19, 2002.

RUMPEL, J.; FELCZYNSKI, K. Effect of plant density on yield and bulb size of direct sown onions. Acta Horticulturae, Bari, v. 533, p. 179-186, 2000.

SANTOS, H. S.; TANAKA, M. T.; WATANABE, S. H.; ARANTES, P. A. Z.; IVONE, T. T. Produção de cebola em função de tamanho de muda e espaçamento.

Horticultura Brasileira, Brasília, v. 18, p. 556-557, 2000. Suplemento.

SEAB/DERAL. Valor bruto da agropecuária paranaense. 2006. Disponível em: <hłtp:/Www.pr.gov.brh seab/deral>. Acesso em: 2 maio 2007.

SILVA, E.; TEIXEIRA, L. A. J.; AMADO, T. J. C. The increase in onion production in Santa Catarina State, South of Brazil. Onion Newsletter for the Tropics, v. 3, p. 7-9, 1991. 
SIQUEIRA, L. G. Densidade e sistema de plantio em cebola, cultivar Serrana e híbrido Mercedes. 2004. 65 f. Dissertação (Mestrado em Fitotecnia) - Universidade Estadual do Sudoeste da Bahia, Vitória da Conquista, 2004.

SOUZA, R. J.; RESENDE, G. M. Cultura da cebola. Lavras: UFLA, 2002. 115 p. (Textos acadêmicos olericultura, 21).
STOFFELLA, P. J. Planting arragement and density of transplants influence sweet spanish onion yields and bulbs size. Hortscience, Amsterdam, v. 31, n. 7, p. 11291130, 1996.

VARGAS, P. F.; BRAZ, L. T.; MAY, A. Produtividade de cultivares de cebola em função do número de mudas por célula de bandeja e espaçamento entre covas. Horticultura Brasileira, Brasília, v. 25, n. 2, p. 241-245, 2007. 